\title{
The Multidimensional Role of Trust in Enabling Creativity within Virtual Communities of Practice: A Theoretical Model Integrating Swift, Knowledge- based, Institution-based, and Organizational Trust
}

\author{
David A. Askay \\ University of North Carolina at Charlotte \\ daskay@uncc.edu
}

\author{
April J. Spivack \\ University of North Carolina at Charlotte \\ April.Spivack@uncc.edu
}

\begin{abstract}
Virtual communities of practice are gaining attention among scholars and practitioners as managers and high-level executives look for ways to adapt to an ever-increasing rate of environmental change. These communities have been recognized as a tool for generating new ideas by accessing geographically distributed expertise. As most expert knowledge is tacit and tacit knowledge exchange is what leads to creativity, an understanding of antecedents to tacit knowledge exchange is needed. This manuscript responds by examining the role of trust, a well-known antecedent of creativity, within the context of virtual communities of practice. An interdisciplinary approach led to the development of a multi-level, multi-dimensional model of trust. The authors propose that different dimensions of trust serve as both an antecedent and outcome of creativity in virtual communities of practice, by taking on various forms and roles in the creative process based on tenure of its members.
\end{abstract}

\section{Introduction}

With increasing frequency, online virtual communities of practice (VCoPs) have sprung up to take advantage of geographically distributed expertise-providing unique opportunities for knowledge exchange and creativity. VCoPs are different from virtual teams, which consist of geographically, organizationally and/or temporally dispersed workers that interact through technologies to accomplish organizational tasks [1] and are often only temporary in nature [2].

Virtual communities, on the other hand, include groups of people that voluntarily interact through computer-mediated communication for professional or social ends [3]. An essential aspect of the virtual community is the development of a sense of virtual community (SOVC) where people have 1) feelings of membership, 2) exchange of support, 3) feelings of attachment and obligation, 4) shared identity, and 5) relationships with specific members [4].

VCoPs are a specialized type of virtual community where "groups of people who share a concern, a set of problems, or a passion about a topic, and who deepen their knowledge and expertise in this area by interacting on an ongoing basis" $[5, \mathrm{p} .4]$ and who primarily do so via computer-mediated communication. These VCoPs tend to revolve around a profession or a specific organization and members find value in sustaining connections with each other, providing opportunities for mentoring, knowledge sharing, emotional support, and problem solving [5]. This allows them to discuss aspirations, needs, and explore ideas. Through time they may create documentation, form collective knowledge, create norms, and cultivate an identity. Examples include dispersed engineers that regularly compare designs and discuss the intricacies of their craft or an online community of educators that discuss best practices in education and develop, share, and review instructional aids and course syllabi.

The internet provides far-reaching accessibility to these communities. The potentially diverse backgrounds and global composition of VCoPs offer fertile ground for bridging gaps between diverse people and forming bonds [6] between similar people - bonds that encourage knowledge sharing [7] and support creativity [8, 9, 10, 11]. Research confirms that higher levels of creativity exist within social networks of weak ties, proposing that this was due to the diversity of information available from a wider network of diverse individuals [9, 12]. Access to the assorted expert knowledge - particularly tacit knowledge-in these communities has been made easier through advances in communication and Web 2.0 applications. Combined with improved internet accessibility across the globe, VCoPs appear well positioned to meet the demand for new ideas and problem solving tools in the rapidly evolving economy. 


\section{Background}

Given the current pressures associated with operating in a global knowledge economy, managers within organizations recognize the necessity of finding ways to proactively and strategically create and manage both explicit and tacit knowledge [13] within and across organizational boundaries $[14,15]$. Both explicit and tacit knowledge are critical in the creation of new knowledge, a necessity for adapting to a constantly changing environment. Traditionally, U.S. organizations have focused on the encoding and exchange of explicit knowledge, such as in the creation and sharing of operating manuals and standard operating procedures, for example. These examples demonstrate how explicit knowledge is easily communicated via formal language. However, tacit knowledge, which is known for having a more significant role in the creative process, contains both cognitive and experiential dimensions, which makes it difficult to readily communicate [13] and often only resides within the minds of area experts. To demonstrate the significantly increased difficulty associated in relaying tacit knowledge, you might ask yourself: how do you explain to someone how to ride a bicycle or to select effective keyword terms for an information search using a search engine.

\subsection{The creative process}

The creative problem solving process can be broken into two main phases: (1) gaining knowledge, which involves the exchange of thought and experience, and (2) using knowledge, which involves ideation and evaluation [16]. Creativity is spurred by exposure to an assortment of knowledge coming from a variety of sources and individuals $[8,10,11]$. This broad exposure allows for information to be integrated and encoded in new ways [17, 18], facilitating the gaining knowledge phase of the creative problem solving process.

In the gaining knowledge phase, phase one, of the creative process, tacit knowledge is the most valuable, yet the most difficult type of knowledge to share. Tacit knowledge has been recognized as a key contribution to a firm's competitive advantage [19] and is an essential component of knowledge exchange that promotes creativity $[20,21,22,23]$. Indeed, the integration and articulation of tacit knowledge creates new knowledge through informal social interactions [13]. In turn, the new knowledge created through tacit knowledge exchange is the most effective type for generating creativity and innovation in groups, considered by some to even be a requirement [24].
Although it has been argued that virtual communities may not support the exchange of tacit knowledge [25, 26, 27, 28], researchers have found that people do indeed contribute knowledge in VCoPs [7, 29]. If any of these contributions are in the form of storytelling [30, 31], a known method by which tacit knowledge may be shared, then tacit knowledge that supports creativity and innovation may be disseminated within virtual communities $[9$, $12,32,33,34]$. Some of the skepticism surrounding the ability to exchange tacit knowledge in online communities has likely been based on the previous limits of technology, such that only typed information could be shared. Researchers have pointed out that tacit knowledge is best shared through emotions, shared experiences, metaphors, analogies, and bodily movements [23]. New waves of Web 2.0 tools are changing the way people interact with and contribute information, so that some of these types of exchanges are possible. For example, verbal and non-verbal information is now available to supplement typed information. Non-verbal communication, such as gestures, facial expressions, and posture can now be observed with video technology. The integration with voice technology has enabled voice cues such as rhythm, tone, and pitch to serve as a tool of information exchange as well.

In addition to allowing for the exchange of new types of information, Web 2.0 technology has allowed for new sources of information. It has become standard practice for users themselves to be entrusted with the creation of content, providing a more dynamic and collaborative process for information sharing [35]. Incorporating these new means of interaction into our conceptualization of the VCoP, we suggest that its loosely organized members can interact using several channels: email, forums, wikis, blogs, podcasts, RSS feeds, instant messaging, chat rooms, web-based conferences, virtual worlds such as SecondLife, and video-sharing sites such as YouTube. These technologies, as well as those that are still in development, have untold possibilities in facilitating tacit knowledge exchange via synchronous and/or asynchronous communication. These tools are increasingly able to provide the rich information that previously was only available to colocated groups.

The second stage of the creativity process involves knowledge use, including ideation and evaluation [16]. As tacit knowledge is shared and new knowledge is generated, the broad knowledge base available in a diverse VCoP allows for intelligent evaluation of these ideas by area experts. 
The Web 2.0 technologies facilitate this evaluation process.

Despite the promising support of creativity that Web 2.0 offers to VCoPs, its usage does result in the introduction of a serious concern: trust. This concern manifests in questions regarding how a user can trust strangers with their ideas and how content created by strangers can be trusted, for example. Also, for idea evaluation to occur, trust in the "judges" of the ideas is needed, and may be difficult when a community is comprised of strangers. Indeed, the literatures of many disciplines, such as innovation, knowledge management, and psychology, have called for research focusing on the role that trust plays in fostering creativity among strangers. For example, one call for research points out that it has yet to be explored whether or not trust is an antecedent or outcome of creativity [36] Likewise, scholars have expressed the need to understand the specific dimensions of trust that play a role in bringing strangers together to share knowledge [29]. Even further, there is a call for understanding the role of trust in different types of online communities [37]. To answer these calls, we integrate multiple theories and frameworks to create an interdisciplinary and multi-level theoretical process model of the relationship between trust and creativity in a $\mathrm{VCoP}$.

\subsection{The role of trust in the creative process}

The development of the KEYS measure of the climate for creativity, identified among six categories of creativity stimulants, three social components: organizational encouragement, supervisory encouragement, and workgroup supports [10]. Within these three social components, knowing that new ideas will receive fair and supportive evaluation was a critical element to supporting creativity. Similarly, a review of organizational creativity literature identified trust and respect for the individual as one of the key dimensions of organizational culture that affects the level of organizational creativity [38]. Likewise, trust is suggested to help create a socially supportive environment by overcoming the barriers of risks associated with knowledge contribution [29].

Creativity is a social process, one that comes about through people and their interactions [39] and the exchange of knowledge $[9,12]$. The importance of trust as a vital antecedent to the knowledge exchange that supports creativity has been wellestablished in the literature. Therefore, it is important to pay attention to the social context of the VCoP and in particular, the role of trust - as both an antecedent and outcome of creativity-between individual members and also between members and the organization.

At first glance, sharing knowledge with strangers seems to be irrational as it benefits others at the expense to the contributor [7, 40,41], who gives their effort and time [7]. There are additional barriers that discourage information contribution, such as the potential misuse of the information, criticism, information freeloading, and loss of competitive advantage [29]. Nonetheless, strangers do contribute knowledge in VCoPs, particularly when opportunities for personal or professional reputation-building and norms of reciprocity exist within the VCoP [7].

And, although many companies work hard to protect their internal knowledge, creativity is most enhanced by strategies supporting knowledge flow rather than strategies to manage and contain knowledge [39]. Armbrecht, et al. [39, p.40] even go on to say that "in today's fast-paced business world, the value created through knowledge sharing appears to outweigh any unreasonable emphasis on secrecy." Nonetheless, in order to facilitate a free-flow of knowledge and realize the creative potential of a $\mathrm{VCoP}$, trust must be present among members.

Having established trust as a necessary precursor for the knowledge exchange that supports creativity, it is essential to examine the multidimensional role of trust among members. Researchers have suggested that several types of trust play a role in knowledge exchange in VCoPs: knowledge-based trust ${ }^{1}$ [29], institution-based trust [29], and organizational trust ${ }^{2}$ [37]. Knowledge-based trust refers to the trust formed from close personal ties over time where a trustor can understand and predict the behavior of the trustee [42, 43, 44, 45]; whereas institution-based trust refers to the belief that institutional structures (e.g. policies, rules, or norms) will protect the trustor [46]. Finally, organizational trust refers to the generalized sense of trust that an individual feels towards the organization as a whole [47]. In VCoPs, organizational trust "develops between an individual and the group of strangers that is community" [37, p.275].

Researchers propose that when VCoPs emerge from existing face-to-face communities, members bring with them the knowledge-based trust that came

\footnotetext{
${ }^{1}$ As is often the case with interdisciplinary research, there are multiple labels that refer to a very similar construct, and although they may not overlap perfectly, we hope that the reader will accept our use of knowledge-based trust to globally refer to what some literatures refer to as 'relational trust', 'affective trust', 'interpersonal trust' or 'identity-based trust' [41].

2 Organizational trust has multiple labels and similar constructs in the literature as well, and even interpersonal trust [43] has been extended to a group-level measure, here we are using organizational trust.
} 
from recurring interactions and learned expectations for behavior of other members [29]. However, most VCoPs are missing many of the qualities of social systems that facilitate trust building, especially when they are comprised of geographically dispersed strangers - such as a physical context that provides opportunities for members to become familiar with one another, share experiences, or fulfill promises [48].

\subsection{Swift trust}

How then is trust developed in VCoPs among strangers and in what of its many forms does it come? When a new member joins a VCoP, researchers propose that these new members rely on institution-based trust - that "necessary structures are in place which will ensure trustworthy behavior of individual members, and protect the members from negative consequences of administrative and procedural mistakes" [29, p.73]. However, the presence of institutional policy does not ensure its enactment [49] and without initial trust in the organization's institutional structures, they may be ineffective at eliciting institution-based trust. So the question remains, how do people initially trust the members and information of a VCoP in the face of its many barriers?

For exploring and understanding this particular scenario, the concept of swift trust provides a promising framework. Swift trust differs from both knowledge-based and organizational trust in that it can be defined as a cognitive and action-oriented form of trust, concerned with "doing" rather than "relating" [48]. And, while the formation of swift trust may benefit from the procedures and structure of the VCoP, it also accounts for uncertainty and the lack of available information on which to base feelings of institution-based trust [48].

Originally developed to explain the trust seen in temporary groups (e.g. theater productions, negotiation teams, or construction teams), swift trust makes the best use of distributed expertise and skills of strangers to accomplish an interdependent and complex task [48]. Perhaps a clear, yet admittedly extreme, example of a situation requiring swift trust is negotiating a hostage situation. Success requires that the captor and negotiator trust each other to fulfill their end of the bargain, but without any prior experience to demonstrate trustworthiness. People must trust each other because the situation demands it for the task at hand to be completed.

Temporary systems, although varying, tend to include participants who: are assembled by a contractor to enact expertise they already possess, have a limited history of working together, from limited labor pools, have limited prospects of working with each other again, are part of overlapping networks, and have a deadline [48]. These temporary system characteristics largely describe the characteristics of VCoPs, making swift trust a logical construct to use as a framework in the new member scenario. This list of characteristics highlights two important factors. First, it is the characteristics of the context or setting that enables swift trust to exist. Second, there is no checklist of conditions to meet, rather the right combination of several possibilities work in unison to allow for the development of swift trust.

Within the context of VCoPs (as well as other types of virtual communities), we propose that the characteristics for enabling swift trust include, but are not necessarily limited to, weak ties, limited history, limited pool of members, and an interdependent task. A new member by definition has a limited history with the community. Also, VCoPs consist of members that are connected by weak ties.

What then is the interdependent task? The answer to this question is found in an individual's motivation for seeking and joining the VCoP. Researchers found, in an empirical study, that the most common reasons people joined a virtual community was for the purpose of exchanging information and receiving social support [50]. If this finding applies to VCoPs as well, then these goals may act in a similar fashion as an interdependent task in temporary groups, thus consistent with the model of swift trust.

In turn, if the initial use of swift trust is rewarded via positive support or useful information, it can "set off a familiar cycle in which trust becomes mutual and reinforcing: trust allows one to engage in certain behaviors, and these behaviors, in turn, reinforce and strengthen members' trust in each other" [48, p.188]. Thus, swift trust is self-reciprocating-much like a deviation-amplifying loop [51] — and provides further opportunities to acquire the experiences necessary to develop knowledge-based, institution-based [29], and organizational trust [37]. It is also these informationseeking or support-seeking motivations that may be the initial driving force leading people to become members of a VCoP.

Finally, swift trust is not necessarily a blind form of trust. Again, it is the context that inhibits a new member from taking advantage of another's trust. The key to this lies in the weak ties present within VCoPs. Potential members arguably seek interaction with each other due to some common interest, which places them in a limited a pool of similar people. This also places their reputation at stake as someone's 
indiscretion can quickly be diffused throughout the social network - to someone with whom they may indeed interact with in the future. This is not to say that it eliminates all possibility of ill-will, but rather underscores a benefit to implementing well thought out reputation management systems for virtual communities.

In summary, within the context of creativity in VCoPs, we propose that swift trust allows for the (1) initial exchange of information, including both tacit and explicit knowledge, (2) creation and expression of creative thought, and (3) evaluation of ideas between strangers and that it is vulnerability to reputations that helps to prevent ill-will. When these initial exchanges are met with a supportive environment, opportunities arise for individuals to develop knowledge-based and organizational trust in the VCoP through a history of positive interactions. These forms of trust can develop because the elements of trustworthiness-ability, benevolence, and integrity $[37,52,53]$ - are demonstrated in these creative exchanges. In turn, the development of organizational trust instills confidence in the structural protections offered by the VCoP in the form of institution-based trust. In other words, whereas some scholars [29] propose that institutionbased trust encourages strangers to share knowledge, we suggest that swift trust is the initial facilitator of creative problem-solving amongst strangers, which then lays the foundation upon which knowledgebased, institution-based, and organizational trust may develop.

This view suggests that trust evolves throughout the lifecycle of a VCoP member, whereby tenure is associated with different forms of trust. Trust starts in a form that allows for quick action and problem resolution (swift), progresses to trust between individuals based on a shared history and interpersonal relationship (knowledge-based) and then finally trust generalizes to the VCoP as a whole (organizational) and its protective structures (institution-based).

Therefore, to fully explore how trust evolves and promotes creativity between members of different tenures, we address the following dyadic scenarios of knowledge exchange/knowledge use: a) new members exchanging knowledge/using knowledge with existing members, b) existing members exchanging knowledge/using knowledge with new members, c) existing members exchanging knowledge/using knowledge with other existing members, and d) new members exchanging knowledge/using knowledge with other new members.

\section{Multidimensional Model of Trust}

To explore the changing role of trust as an enabler of creativity in a $\mathrm{VCoP}$ and in an attempt to provide a framework for exploring the above scenarios, we present a theoretical process model below. This model presents a proposed pathway for the transformation of swift trust into opportunities to exchange and use knowledge, as the two key phases of the creative process, which in turn allow for the development of knowledge-based, institution-based, and organizational trust over time (Figure 1).

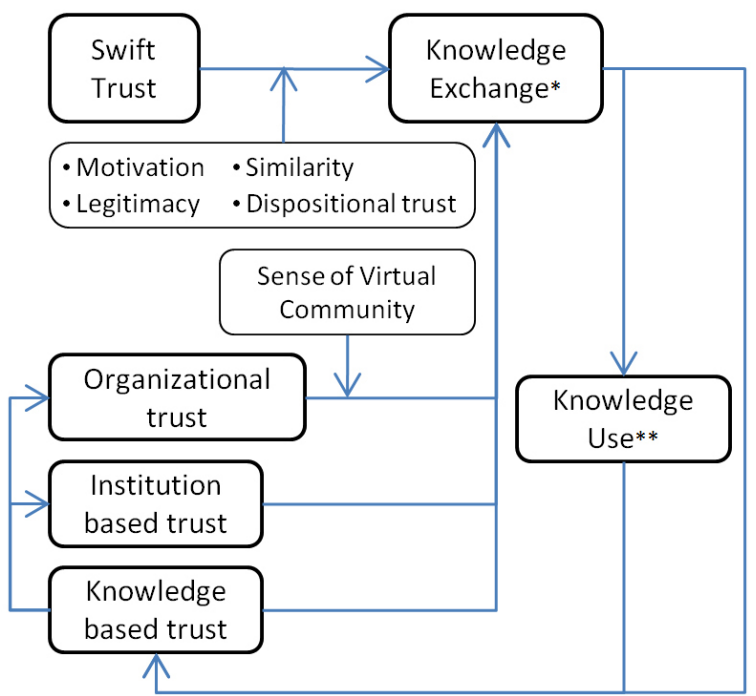

Figure 1. The evolving role of trust in enabling creativity in a virtual community of practice. ( ${ }^{\star}$ Phase I, ${ }^{*}$ Phase II of the creative process)

\subsection{New members sharing ideas with existing members}

First, we assume that a new member has joined the VCoP in search of knowledge or social support [50]. This individual has joined with some initial perceptions of the reputation of and expertise present within the VCoP. In addition, new members will likely explore the $\mathrm{VCoP}$ and personal identity cues available on the site. These cues may include the degree of perceived trustworthiness based on the appearance of the website and member profiles. Profiles may include such information as member names, photos, friends, communications, evaluations or ratings assigned by other members, and community designations.

The new member will search profiles for indicators of trustworthiness, previously defined as 
ability, benevolence, and integrity $[37,52,53]$. The new member may also make judgments based on the appearance of the profiles, attractiveness of other members [54], the quality, quantity, and personal nature of the content provided in the text of the profiles, and the individual similarities between the new member and existing members. When taken together, all of this information serves to decrease feelings of vulnerability, uncertainty, and risk [48] for the newcomer, each of which is recognized as an obstacle to trust formation.

When trusting someone, vulnerability exists in the form of possibly receiving ill-will from them [55]; whereas uncertainty is the estimation of whether someone will do something beneficial or harmful to the new member before knowing for sure [48]. Without being able to monitor people over time, it can be difficult to overcome these two components. However, scholars suggest that when there is a mutual threat to reputations, it lays "the grounds for participants to expect and be receptive to trust and trustworthiness" [48, p.172]. This suggests that in a $\mathrm{VCoP}$, some protection from ill-will is created through the network of weak ties where one's reputation is bridged to diverse members. Indeed, reputation-building was found to be an important factor leading to sharing knowledge in virtual communities [7]. Reputation, it appears, is an invaluable asset and the gateway to creative interaction.

The third component that must be overcome is risk, which evolves choosing to accept a situation where the possible damage may outweigh the benefits [56]. Trust "presupposes a situation of risk" [56, p.178] because if one was certain about the outcome of a situation there would be no risk involved and thus, no need for trust. The only way to avoid risk is through inaction (e.g. not sharing information). Inaction, however, has its own drawback: it precludes receiving the information or support that may have initially motivated the new member to join a VCoP [50]. Likewise, the wrong action (e.g. ill-will) can damage one's reputation [56]. However, if risk is accepted and leads to a positive outcome, risk-taking behavior is rewarded, which could increase a member's willingness to accept risk from members of the same VCoP [48].

Swift trust enables the reduction in feelings of vulnerability, uncertainty, and risk to allow for creative exchanges among strangers. Again, swift trust is important in the $\mathrm{VCoP}$ because for new members, knowledge-based, institution-based, and organizational trust have not yet had an opportunity to develop. Swift trust enables cognitive and actionoriented trust, fostering initial knowledge exchange.
The model shows knowledge exchange and knowledge use as two separately enacted parts of the creative process, in line with current creativity research [16]. We suggest that trust will play a role mostly through the first phase, which then allows for phase two, knowledge use, which includes developing, sharing, and evaluating creative ideas. We propose that knowledge exchange occurs with minimal passage of time and investment, as a result of swift trust. Thus, we propose the following:

Proposition 1a: New members exchange knowledge with existing members based on swift trust.

Proposition 1b: Members use knowledge in ideation and evaluation activities with other members once knowledge exchange has occurred.

\subsection{Existing members sharing ideas with new members}

What kind of information do existing members use to evaluate the trustworthiness of new members? This is a key question relevant to knowledge sharing in VCoPs. Indeed, different sub-groups of existing users may be more willing to connect with and trust new members. Existing members, having a history of successful interactions with other members and the organization, are expected to trust new members with institution-based and organizational trust. Finally, established members are expected to have a reputation, which plays a crucial role in providing a legitimate endorsement to new members [57].

Institution-based trust allows existing members to trust new members based on the established norms of the VCoP, such as norms of reciprocity. Norms of reciprocity form when one community member helps another and can expect to be helped in return [58]. Additionally, these norms offer protection to the community's members as they set the stage for expected social behaviors [37, 59, 60], which can lead to organizational trust. Together these conditions lead to the following two propositions:

Proposition 2a: Existing members exchange knowledge with new members using institution-based trust.

Proposition 2b: Existing members exchange knowledge with new members using organizational trust.

\subsection{Existing members sharing ideas with other existing members}

Interaction between existing members is essential to the success of a VCoP. These members 
spread norms and contribute to the legitimacy of the VCoP, helping to build knowledge-based, institutionbased, and organizational trust. There are two types of existing member interactions: initial interactions with unfamiliar members and those continuing with familiar members.

The dynamics of the initial interaction with an existing member differs from that of a new member. Whereas there may be no direct past interactions between existing members, the weak ties of a VCoP may carry reputation information. This can come in the form of mutual friends, profile information, or even reviewing the history of members. Depending on the depth (and tenure) of information available about the existing member swift trust may not be needed. Instead, trustworthiness is imported from institution-based and organizational trust, such as reputation, community designations, and norms.

However, when an existing member continues a history of interactions with a known member, this is suggestive of knowledge-based trust resulting from reputation, familiarization, past shared experiences, demonstrated expertise, and reciprocation. Each of these promotes the trustworthiness of membersdemonstrating ability, benevolence, and integrity [37, $52,53]$. This leads to the ability of members to form institution-based and organizational trust.

Still, an existing member may have formed sufficient institution-based and organizational trust to rely on these cues. This brings up an interesting point: which form of trust is more powerful? We propose that, in the end, VCoPs thrive from interpersonal interactions between two people. Therefore, in this case knowledge-based trust (or distrust) is expected to have a stronger influence on deciding trustworthiness of an existing member. Therefore we present the following propositions:

Proposition 3a: Existing members exchange knowledge with unfamiliar existing members based on institution-based trust.

Proposition 3b: Existing members exchange knowledge with unfamiliar existing members based on organizational trust.

Proposition 3c: Existing members exchange knowledge with other familiar existing members via knowledge-based trust.

\subsection{New members sharing ideas with other new members}

There is an intriguing contradiction in the dynamics of new members trusting new members.
On the one hand, new members may lack sufficient reputation or experience to convey trustworthiness to other new members. On the other hand, their mutual inexperience may cause them to see each other as more similar, thus more likely to trust together [61, 62]. This leads us to the following proposition:

Proposition 4: New members exchange knowledge with other new members based on swift trust.

\subsection{Potential Moderating Relationships}

An exhaustive discussion of potential moderators of the relationships proposed in the model is outside the scope of this paper, but as illustrative examples, we present a few potential moderators based on previous research.

In situations where swift trust is proposed, the lack of information to judge trustworthiness may cause other cues to become more salient among new or existing unfamiliar members. For example, new members may lack sufficient reputation to convey trustworthiness to other members. The literature suggests a few potential moderators for this situation.

First, perceived similarity can result in more positive impressions of others and thus more likely to engage in trust $[61,62]$. Second, if motivation to exchange information is great, it may reduce the amount of trustworthiness cues needed to exchange this information [63]. Finally, the actions of existing members may have a profound impact on the recruitment of new members. This would impact the perceived legitimacy of the $\mathrm{VCoP}$ and increase (or decrease) the willingness of members to trust each other $[64,65]$. This leads us to the following propositions:

Proposition 5: New/unfamiliar existing members exchange knowledge with other new/unfamiliar existing members through swift trust, moderated by level of similarity between members.

Proposition 6: New/unfamiliar existing members exchange knowledge with other new/unfamiliar existing members through swift trust, moderated by intensity of motivation for information exchange.

Proposition 7: New/unfamiliar existing members exchange knowledge with other new/unfamiliar existing members through swift trust, moderated perceived legitimacy of the VCoP.

Another source of influence in our model is when existing members possess a sense of virtual community $[3,4]$. Through time, members of virtual communities begin to have feelings of identity, 
belonging, and attachment to the community. This could decrease their perception of vulnerability, uncertainty, and risk due to their own close ties to the VCoP. As such, they may accept new members as legitimate, via organizational trust. This leads us to the following proposition:

Proposition 8: Existing members exchange knowledge with new members using organizational trust, moderated by sense of virtual community.

Dispositional trust is a construct that has been used to explain initial trust between strangers [46, 66]. It represents an individual difference in the amount of risk a person is generally willing to accept and reflects their trust in humanity. However, there have been inconclusive results in the literature as to the importance of dispositional trust in developing relationships: some report that it is necessary [52], whereas other studies found that it is not [67,68]. These mixed results suggest the possibility that disposition may be context-dependent, which would then integrate well within the model of swift trust. This leads us to the following proposition:

Proposition 9: Dispositional trust is a moderator between swift trust and knowledge exchange.

There may indeed be other moderators of interest that future research should explore, such as experience with online communities, generational differences, or technological features of the community, such as the type of information provided in a reputation management system.

\section{Testing the Model}

Although this paper focuses on developing a theoretical model, a discussion of testing the model is in order. Several of the constructs discussedknowledge-based trust, organizational trust, and institution-based trust-have established quantitative scales [69]. However, the contextual nature of swift trust lends itself more to a qualitative measurement approach. Also, to test this model, longitudinal data will need to be used, so that a determination of the order in which each type of trust is developed can be made. For these reasons, the authors plan to employ a mixed methods approach to a case study of a VCoP through its formative stages, using a combination of qualitative in-depth interviews and quantitative surveys.

\section{Conclusions}

A virtual community of practice is a modern context of social interaction that has the potential to serve as a hotbed for creativity. These communities provide the opportunity for weak ties to rapidly form between diverse individuals who share an area of interest. The technologies available to $\mathrm{VCoPs}$ have matured to allow for the easy exchange of knowledge, ideas, and excitement [38] among members (i.e., Web 2.0 applications). To fully take advantage of the creative potential of VCoPs, a deeper understanding of the antecedents to creative output is needed.

We present a model that conceptualizes the role of one of the most widely-acknowledged antecedents of creativity-trust. We called upon multiple disciplines in the understanding of the concept of trust, such as psychology, knowledge management, and creativity. Integrating theories and concepts from each of these disciplines, we developed a multi-level, multidimensional process model of the evolution of trust amongst members of different tenures in a VCoP.

The proposed model can be used to study the relationships between factors influencing the development of swift, knowledge-based, institutionbased, and organizational trust and their impact on creative output. The model presented in this paper should be applicable to any other outcome variables in VCoPs that have trust as an antecedent, such as team performance or safety. Furthermore, issues of trust are not exclusive to $\mathrm{VCoPs}$ and thus these results are expected to generalize to other types of virtual communities.

Finally, this paper answers several calls for research in this area, such as the call from Gilson [36] to establish trust as an outcome or antecedent of creativity. Our model predicts that it is both: swift trust is used by new members to support knowledge exchange until there is a foundation upon which knowledge-based trust can form between members and institution-based and organizational trust of the $\mathrm{VCoP}$ itself can develop.

\section{References}

[1] A. Powell, G. Piccoli, and B. Ives, "Virtual teams: a review of current literature and directions for future research", The DATA BASE for Advances in Information Systems, 2004. 35(1): pp. 6-36.

[2] N. Chase, "Learning to lead a virtual team", Journal of Quality, 1999. 38(9): pp. 76.

[3] A. Blanchard, "Testing a model of sense of virtual community", Computers in Human Behavior, 2008. 24(5): pp. 2107-2123. 
[4] A. Blanchard and M. Markus, "The experienced" sense" of a virtual community: characteristics and processes", ACM SIGMIS Database, 2004. 35(1): pp. 64-79.

[5] E. Wenger, R.A. McDermott, and W. Snyder, Cultivating communities of practice: A guide to managing knowledge. 2002, Boston, MA: Harvard Business School Press.

[6] P. Dekker and E.M. Uslaner, Social capital and participation in everyday life. 2001, London: Routledge.

[7] M. McLure Wasko and S. Faraj, "Why Should I Share? Examining Social Capital and Knowledge Contribution in Electronic Networks of Practice", MIS Quarterly, 2005. 29(1): pp. 35-57.

[8] R.W. Woodman, J.E. Sawyer, and R.W. Griffin, "Toward a theory of organizational creativity", The Academy of Management Review, 1993. 18(2): pp. 293-321.

[9] J.E. Perry-Smith, "Social yet creative: The role of social relationships in facilitating individual creativity", The Academy of Management Journal, 2006. 49(1): pp. 85-101.

[10] T.M. Amabile, R. Conti, H. Coon, J. Lazenby, and M. Herron, "Assessing the Work Environment for Creativity", The Academy of Management Journal, 1996. 39(5): pp. 1154-1184.

[11] C.M. Ford, "A theory of individual creative action in multiple social domains", The Academy of Management Review, 1996. 21(4): pp. 11121142.

[12] J.E. Perry-Smith and C.E. Shalley, "The social side of creativity: A static and dynamic social network perspective", The Academy of Management Review, 2003. 28(1): pp. 89-106.

[13] I. Nonaka, "A dynamic theory of organizational knowledge creation", Organization Science, 1994. 5(1): pp. 14-37.

[14] J.S. Brown and P. Duguid, "Knowledge and Organization: A Social-Practice Perspective", Organization Science, 2001. 12(2): pp. 198-213.

[15] J.S. Brown and P. Duguid, The social life of information. 2002, Cambridge: Harvard Business School Press.

[16] M. Basadur, "Identifying Individual Differences in Creative Problem Solving Style", Journal of Creative Behavior, 1990. 24(2): pp. 111-31.

[17] A.F. Osborn, Applied imagination. 1963, New York: Scribner's.

[18] S.J. Parnes and R.B. Noller, "Applied Creativity: The Creative Studies Project: Part II--Results of the Two-Year Program", Journal of Creative Behavior, 1972. 6(3): pp. 164-186.

[19] L. Argote and P. Ingram, "Knowledge transfer: A basis for competitive advantage in firms", Organizational behavior and human decision processes, 2000. 82(1): pp. 150-169.

[20] D. Leonard and S. Sensiper, "The role of tacit knowledge in group innovation", Knowledge and Strategy, 1999: pp. 281-281.
[21] M.A. Boden, Dimensions of creativity. 1994, Cambridge, MA: MIT Press.

[22] R. Mascitelli, "From experience: harnessing tacit knowledge to achieve breakthrough innovation", Journal of Product Innovation Management, 2000. 17(3): pp. 179-193.

[23] I. Nonaka and H. Takeuchi, The knowledge-creating company. 1995, New York: Oxford University Press.

[24] I. Alony and M. Jones. Tacit Knowledge, Explicability and Creativity-A Study of the Australian Film Industry. in Proceedings of the Experiential Knowledge Conference. 2007. Hatfield, UK.

[25] J.S. Brown and P. Duguid, "Organizing Knowledge", CALIFORNIA MANAGEMENT REVIEW, 1998. 40(3): pp. 91-91.

[26] M.S. Gertler, "Tacit knowledge and the economic geography of context, or the undefinable tacitness of being (there)", Journal of economic geography, 2003. 3(1): pp. 75-99.

[27] T. Haldin-Herrgard, "Difficulties in diffusion of tacit knowledge in organizations", Journal of Intellectual Capital, 2000. 1(4): pp. 357-365.

[28] W.J. Orlikowski, "Knowing in practice: Enacting a collective capability in distributed organizing", Organization Science, 2002. 13(3): pp. 249-273.

[29] A. Ardichvili, V. Page, and T. Wentling, "Motivation and barriers to participation in virtual knowledgesharing communities of practice", Journal of Knowledge Management, 2003. 7(1): pp. 64-77.

[30] C. Linde, "Narrative and social tacit knowledge", Journal of Knowledge Management, 2001. 5(2): pp. 160-170.

[31] W. Swap and D. Leonard, "Using mentoring and storytelling to transfer knowledge in the workplace", Journal of Management Information Systems, 2001. 18(1): pp. 95-114.

[32] J.S. Brown and P. Duguid, "Organizational learning and communities-of-practice: Toward a unified view of working, learning, and innovation", Organization Science, 1991. 2(1): pp. 40-57.

[33] L. Araujo, "Knowing and learning as networking", Management Learning, 1998. 29(3): pp. 317-317.

[34] K.E. Weick and F. Westley, Organizational learning: Affirming an oxymoron, in Handbook of organization studies, S.R. Clegg, C. Hardy, and W.R. Nord, Editors. 1996, Sage: London. pp. 440-458.

[35] L. Tredinnick, "Web 2.0 and Business: A pointer to the intranets of the future?", Business information review, 2006. 23(4): pp. 228-228.

[36] L.L. Gilson, Why Be Creative: A Review of the Practical Outcomes Associated with Creativity at the Individual, Group, and Organizational Levels, in Handbook of organizational creativity, J. Zhou and C. Shalley, Editors. 2008, Lawrence Erlbaum Associates: New York. pp. 317.

[37] C.M. Ridings, D. Gefen, and B. Arinze, "Some antecedents and effects of trust in virtual communities", Journal of Strategic Information Systems, 2002. 11(3-4): pp. 271-295. 
[38] C. Andriopoulos, "Determinants of organizational creativity: a literature review", Management Decision, 2001. 39(10): pp. 834-840.

[39] F.M.R. Armbrecht Jr, R.B. Chapas, C.C. Chappelow, G.F. Farris, P.N. Friga, C.A. Hartz, M.E. McIlvaine, S.R. Postle, and G.E. Whitwell, "Knowledge management in research and development", Research Technology Management, 2001. 44(4): pp. 28-48.

[40] J.W. Thibaut and H.H. Kelley, The social psychology of groups. 1986, New Brunswick, NJ: Transaction Publishers.

[41] B.K. Thorn and T. Connolly, "Discretionary data bases: A theory and some experimental findings", Communication Research, 1987. 14(5): pp. 512512.

[42] R. Gulati, "Does familiarity breed trust? The implications of repeated ties for contractual choice in alliances", The Academy of Management Journal, 1995. 38(1): pp. 85-112.

[43] P. Ratnasingham, "The importance of trust in electronic commerce", Internet Research: Electronic Networking Applications and Policy, 1998. 8(4): pp. 313-21.

[44] D.L. Shapiro, B.H. Sheppard, and L. Cheraskin, "Business on a handshake", Negotiation Journal, 1992. 8(4): pp. 365-377.

[45] D.M. Rousseau, S.B. Sitkin, R.S. Burt, and C. Camerer, "Not so different after all: A crossdiscipline view of trust", The Academy of Management Review, 1998. 23(3): pp. 393-404.

[46] D.H. McKnight, L.L. Cummings, and N.L. Chervany, "Initial trust formation in new organizational relationships", The Academy of Management Review, 1998. 23(3): pp. 473-490.

[47] S.L. Jarvenpaa, K. Knoll, and D.E. Leidner, "Is anybody out there?: antecedents of trust in global virtual teams", Journal of Management Information Systems, 1998. 14(4): pp. 29-64.

[48] D. Meyerson, K.E. Weick, and R.M. Kramer, Swift Trust and Temporary Groups, in Trust in Organizations: Frontiers of Theory and Research, R.M. Kramer and T.R. Tyler, Editors. 1996, Sage Publications, Inc: Thousand Oaks, CA. pp. 166195.

[49] E. Kirby and K. Krone, "'" The policy exists but you can't really use it": communication and the structuration of work-family policies", Journal of Applied Communication Research, 2002. 30(1): pp. 50-77.

[50] C.M. Ridings and D. Gefen, "Virtual community attraction: Why people hang out online", Journal of Computer-Mediated Communication, 2004. $10(1)$.

[51] K.E. Weick, The Social Psychology of Organizing. 1979, New York: Random House.

[52] R.C. Mayer, J.H. Davis, and F.D. Schoorman, "An integrative model of organizational trust", The Academy of Management Review, 1995. 20(3): pp. 709-734.
[53] F.D. Schoorman, R.C. Mayer, and J.H. Davis, "An integrative model of organizational trust: Past, present, and future", The Academy of Management Review, 2007. 32(2): pp. 344-354.

[54] J.B. Walther, C. Slovacek, and L.C. Tidwell, "Is a picture worth a thousand words? Photographic images in long term and short term virtual teams", Communication Research, 2001. 28(1): pp. 105-134-105-134.

[55] A. Baier, "Trust and antitrust", Ethics, 1986. 96(2): pp. 231-260.

[56] N. Luhmann and D. Gambetta, Trust: Making and breaking cooperative relations. 1988: Blackwell New York.

[57] P. Kollock and M.A. Smith, Communities in cyberspace. 1998, New York: Routledge London.

[58] A. Gouldner, "The norm of reciprocity: A preliminary statement", American sociological review, 1960. 25(2): pp. 161-178.

[59] A. Blanchard and T. Horan, "Virtual communities and social capital", Social Science Computer Review, 1998. 16(3): pp. 293-293.

[60] R.M. Kramer, "Trust and distrust in organizations: Emerging perspectives, enduring questions", Annual review of psychology, 1999. 50(1): pp. 569-598.

[61] C.N. Ziegler and J. Golbeck, "Investigating correlations of trust and interest similarity-do birds of a feather really flock together", Decision Support Systems, 2005.

[62] J. Golbeck, "Trust and nuanced profile similarity in online social networks", Journal of Artificial Intelligence Research, 2006.

[63] K. Dirks and D. Ferrin, "The role of trust in organizational settings", Organization Science, 2001. 12(4): pp. 450-467.

[64] M. Suchman, "Managing legitimacy: Strategic and institutional approaches", The Academy of Management Review, 1995. 20(3): pp. 571-610.

[65] R. Jepperson, Institutions, institutional effects, and institutionalism, in The new institutionalism in organizational analysis, W. Powell and P. DiMaggio, Editors. 1991, University of Chicago Press: Chicago, IL. pp. 143-163.

[66] J. Rotter, "Generalized expectancies for interpersonal trust", American Psychologist, 1971. 26(5): pp. 443-452.

[67] C. Johnson-George and W. Swap, "Measurement of specific interpersonal trust: Construction and validation of a scale to assess trust in a specific other", Journal of Personality and Social Psychology, 1982. 43(6): pp. 1306-1317.

[68] J. Holmes, Trust and the appraisal process in close relationships, in Advances in personal relationships: A research annual, W.H. Jones and D. Perlman, Editors. 1991, Jessica Kingsley: London. pp. 57-104.

[69] D. McKnight, V. Choudhury, and C. Kacmar, "Developing and validating trust measures for ecommerce: An integrative typology", Information Systems Research, 2002. 13(3): pp. 334-359. 